\title{
Ursolic acid sensitizes radioresistant NSCLC cells expressing HIF-1 $\alpha$ through reducing endogenous GSH and inhibiting HIF-1 $\alpha$
}

\author{
BING SONG $^{1^{*}}$, QIAN ZHANG ${ }^{2 *}$, MAOHU YU ${ }^{2}$, XINRONG QI ${ }^{2}$, \\ GANG WANG $^{2}$, LINLIN XIAO ${ }^{2}$, QIYI YI ${ }^{2}$ and WENSEN JIN ${ }^{2}$ \\ ${ }^{1}$ Department of Cardiology, First Affiliated Hospital, Anhui Medical University; \\ ${ }^{2}$ Teaching and Research Section of Nuclear Medicine, Anhui Medical University, Hefei, Anhui 230032, P.R. China
}

Received April 18, 2015; Accepted October 26, 2016

DOI: $10.3892 / \mathrm{ol} .2016 .5468$

\begin{abstract}
In previous studies, the present authors demonstrated that effective sensitization of ionizing radiation-induced death of tumor cells, including non-small cell lung cancer (NSCLC) cells, could be produced by oleanolic acid (OA), a pentacyclic triterpenoid present in plants. In the present study, it was investigated whether ursolic acid (UA), an isomer of OA, had also the capacity of sensitizing radioresistant NSCLC cells. The radioresistant cell line H1299/M-hypoxia inducible factor-1 $\alpha$ (HIF-1 $\alpha$ ) was established by transfection with a recombinant plasmid expressing mutant HIF-1 $\alpha$ (M-HIF-1 $\alpha$ ). Compared with parental H1299 cells and H1299 cells transfected with empty plasmid, H1299/M-HIF-1 $\alpha$ cells had lower radiosensitivity. Following the use of UA to treat NSCLC cells, elevation of the radiosensitivity of cells was observed by MTT assay. The irradiated H1299/M-HIF-1 $\alpha$ cells were more sensitive to UA pretreatment than the irradiated cells with empty plasmid and control. The alteration of DNA damage in the irradiated cells was further measured using micronucleus (MN) assay. The combination of UA treatment with radiation could induce the increase of cellular MN frequencies, in agreement with the change in the tendency observed in the cell viability assay. It was further shown that the endogenous glutathione (GSH) contents were markedly attenuated in the differently irradiated NSCLC cells with UA $(80 \mu \mathrm{mol} / \mathrm{l})$ pretreatment through glutathione reductase/5,5'-dithiobis-(2-nitrob-enzoic acid) (DTNB) recycling assay. The results revealed that UA treatment alone could effectively decrease the GSH content in H1299/M-HIF-1 $\alpha$ cells. In addition, the inhibition of HIF-1 $\alpha$ expression in radioresistant cells was confirmed by western
\end{abstract}

Correspondence to: Professor Wensen Jin, Teaching and Research Section of Nuclear Medicine, Anhui Medical University, 81 Mei-Shan Road, Hefei, Anhui 230032, P.R. China

E-mail: wensenjn@139.com

${ }^{*}$ Contributed equally

Key words: ursolic acid, radiosensitization, non-small cell lung cancer, glutathione, hypoxia inducible factor- $1 \alpha$ blotting. It was then concluded that UA could upregulate the radiosensitivity of NSCLC cells, and in particular reduce the refractory response of cells expressing HIF-1 $\alpha$ to ionizing radiation. The primary mechanism is associated with reduction of endogenous GSH and inhibition of high expression of intracellular HIF-1 $\alpha$. UA should therefore be deeply studied as a potential radiosensitizing reagent for NSCLC radiotherapy.

\section{Introduction}

Radiotherapy is an established treatment modality for non-small cell lung cancer (NSCLC), which can provide an effective cure for a proportion of patients (1). Although NSCLC is a moderately radiation-responsive tumor, local control is still not achieved in numerous patients, primarily due to intrinsic and acquired resistance of tumor cells to ionizing radiation $(2,3)$. There are difficulties in delivering sufficiently high radiotherapy doses to the tumor due to potential toxicity development in the normal tissue (4). Therefore, it is particularly beneficial for radiotherapy of NSCLC to increase the radiosensitivity of resistant NSCLC cells by using natural or synthetic compounds.

Local failure of radiotherapy is associated with a series of factors, where the radiosensitivity of irradiated cells depends on a complex interplay of nuclear and cytoplasmic signaling cascades (5-8). Ionizing radiation induces DNA double-strand breakages (DSBs) and production of free radicals (FRs) and reactive oxygen species (ROS), which can cause DSBs of DNA and lipid oxidation of the cellular membrane; these events are widely acknowledged as the principal determinants of radiation-induced cell death $(9,10)$. Intracellular antioxidants such as the tripeptide thiol L- $\gamma$-glutamyl-L-cysteinyl-glycine (glutathione, GSH) play a key role in the protection of cells against the oxidative stress induced by FR and ROS (11). GSH, which is present in all mammalian cells, is the most important intracellular thiol-based scavenger of FR and ROS (12-14). The level of GSH is increased in various tumor cells, including NSCLC cells $(15,16)$. Agents that decrease the cellular content of GSH could effectively inhibit the DNA damage repair to increase the response of tumor cells to ionizing radiation $(17,18)$.

Numerous compounds extracted from natural sources have been observed to elevate the radiosensitivity of tumor cells $(19,20)$. Ursolic acid (3-beta-hydroxy-urs-12-en-28-oic acid, UA) is one of the pentacyclic triterpenoids that exist widely 
in the plant kingdom (Fig. 1) (21). UA is a compound of interest in oncology research due to its cytotoxicity, its anti-invasive and anti-migration activities, and its ability to induce cell differentiation $(22,23)$. UA also interferes with damage repair of cancer cells and induces apoptosis in cancer cells by regulating different signaling pathways, including inhibition of $\mathrm{Wnt} / \beta$-catenin and activation of the c-Jun N-terminal kinase and the phosphoinositide 3-kinase/Akt/nuclear factor (NF)- $\kappa \mathrm{B}$ signaling pathways (24-26). Previous studies have demonstrated sensitization caused by UA towards chemotherapy and radiotherapy (27-29). With regard to the treatment of NSCLC, chemosensitization to low doses of UA was found in the ASTC-a-1 cell line (human lung adenocarcinoma cells) through suppression of $\mathrm{NF}-\kappa \mathrm{B}(27)$. However, it remains unclear whether the radiosensitivity of NSCLC cells, particularly that of cells with refractory response to radiation, could be increased by UA. In present study, a radioresistant NSCLC cell line was established by transfecting a mutant HIF-1 $\alpha$ (M-HIF-1 $\alpha$ ) plasmid, and the radiosensitivity of the parental and radioresistant NSCLC cells was investigated upon UA pretreatment. In order to preliminarily analyze the mechanism, the alteration of intracellular GSH level was also analyzed.

\section{Materials and methods}

Cell culture and treatment. The human lung cancer H1299 cell line was kindly provided by Professor Qinghua Shi (College of Biological Science, University of Science and Technology of China, Hefei, China). Cells were maintained in Dulbecco's modified Eagle medium (Gibco; Thermo Fisher Scientific, Inc., Waltham, MA, USA) supplemented with $10 \%$ fetal bovine serum (Gibco; Thermo Fisher Scientific, Inc.), penicillin (100 U/ml) and streptomycin $(100 \mu \mathrm{g} / \mathrm{ml})$ (Sigma-Aldrich, St. Louis, MO, USA) at $37^{\circ} \mathrm{C}$ in an incubator containing a humid atmosphere of $95 \%$ air and $5 \% \mathrm{CO}_{2}$, and propagated according to the protocol supplied by the American Type Culture Collection (Manassas, VA, USA). UA was purchased from Nanjing Zelang Medical Technology Co., Ltd. (Nanjing, China), dissolved in dimethyl sulfoxide (DMSO; Sigma-Aldrich) at a stock concentration of $5 \mathrm{mmol} / \mathrm{l}$ and stored at $-20^{\circ} \mathrm{C}$.

Plasmids and transfection assays. The pcDNA3.0 vector with enhanced green fluorescence protein (EGFP) was kindly provided by Professor Qinghua Shi. HIF-1 $\alpha$ complementary DNA(cDNA) for with three mutant motifs, including the prolines at the 402 and 564 sites in the oxygen-dependent degradation domain (ODDD) of HIF-1 $\alpha$, and the aspartic acid at the 803 site in the C-terminal transactivation domain (CTAD) of HIF-1 $\alpha$, was purchased from Beijing Zhongyuan Ltd. (Beijing, China). The M-HIF-1 $\alpha$ cDNA was cloned into the pcDNA3.0-EGFP vector to construct the pcDNA3.0-EGFP-HIF-1 $\alpha$ recombinant plasmid. The pcDNA3.0-EGFP empty vector was used as control. H1299 cells $\left(5 \times 10^{5}\right)$ were transfected with $4 \mu \mathrm{g}$ plasmid DNA using Lipofectamine 2000 (Invitrogen; Thermo Fisher Scientific, Inc.), according to the manufacturer's protocol. The neomycin-resistant clones were selected in DMEM (Gibco; Thermo Fisher Scientific, Inc.) containing $500 \mu \mathrm{g} / \mathrm{ml} \mathrm{G} 418$ (Promega Corporation, Madison, WI, USA), and transferred into a 24-well culture plate with cloning discs (Sigma-Aldrich). The selected clones were expanded in medium containing

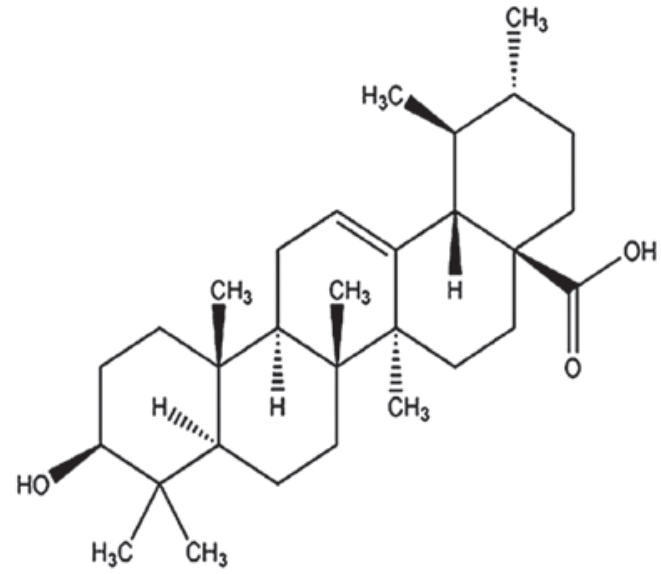

Figure 1. Chemical structure of ursolic acid. Image adapted from Zang et al (21).

$200 \mu \mathrm{g} / \mathrm{ml} \mathrm{G} 418$, and identified by detecting the messenger RNA and protein expression of M-HIF-1 $\alpha$.

Cell viability assay. The influence of UA on cell growth was determined using the MTT (Sigma-Aldrich) assay. The parental H1299 cells and H1299 cells expressing the M-HIF-1 $\alpha$ fragment were seeded in 96-well plates at a density of $5 \times 10^{3}$ cells/well, and then treated with various concentrations of UA for $24 \mathrm{~h}$. Next, the medium was replaced with fresh medium to allow cells to continuously grow for $72 \mathrm{~h}$. MTT dye was then added to a final concentration of $50 \mathrm{mg} / \mathrm{ml}$, and the cells were subsequently incubated for additional $4 \mathrm{~h}$ at $37^{\circ} \mathrm{C}$. The medium containing residual MTT dye was carefully aspirated from each of the wells, and $200 \mu$ l dimethyl sulfoxide was added to each well to dissolve the reduced formazan dye. The survival rates of viable cells were calculated by comparing the optical absorbance of the culture exposed to UA treatment with that of the untreated control.

Irradiation. Irradiation was emitted using a 6 MV X-ray linear accelerator (Varian Inc., Palo Alto, CA, USA) at a dose rate of $250 \mathrm{cGy} / \mathrm{min}$.

Micronucleus (MN) assay. MN frequencies were tested with the cytokinesis-block technique as a biological end point for the response of mimetic hypoxia to irradiation (30). Briefly, the cells were exposed to $0.83 \mu \mathrm{g} / \mathrm{ml}$ cytochalasin B (Sigma-Aldrich) for $19-20 \mathrm{~h}$, followed by $75 \mathrm{mM} \mathrm{KCl}$ hypotonic treatment for 1-3 min, and then fixed in situ with methanol:acetic acid (9:1 v/v) for $30 \mathrm{~min}$. Air-dried cells were stained with $5 \%$ Giemsa for $10 \mathrm{~min}$. MN were scored in binucleated cells, and the formation of binucleated cells was measured as the percentage of the total number of cells scored. For each sample, $\geq 1,000$ binucleated cells were counted. The $\mathrm{MN}$ yield was calculated as the ratio of the number of $\mathrm{MN}$ to the number of binucleated cells scored.

Western blot analysis of HIF-1 $\alpha$ expression. Cells subjected to different treatments were scraped off from culture flasks and lysed in lysis buffer containing $10 \%$ glycerol, $10 \mathrm{mM}$ Tris- $\mathrm{HCl}$ (pH 6.8), $1 \%$ sodium dodecyl sulfate (SDS), 5 mM dithiothreitol and $1 \mathrm{X}$ complete protease inhibitor cocktail (Sigma-Aldrich). 
A

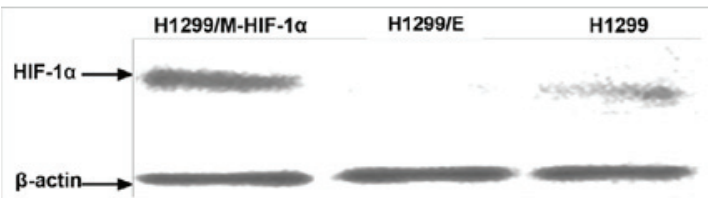

B

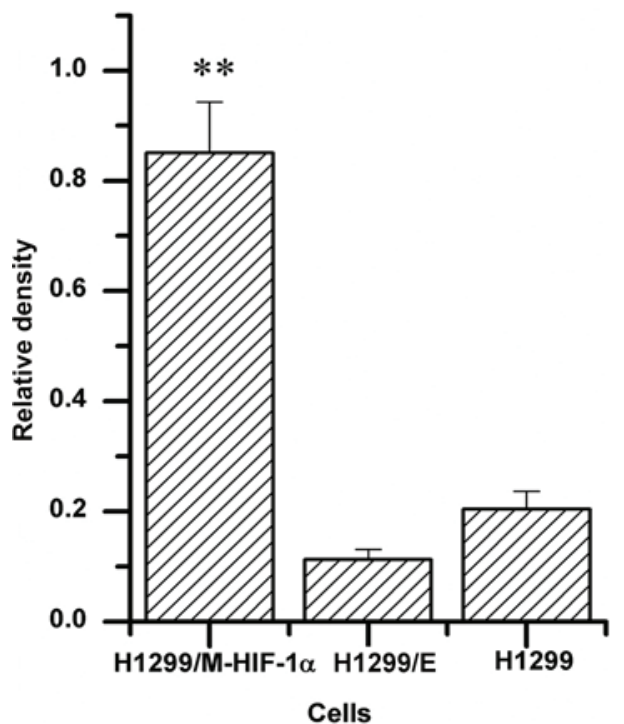

C

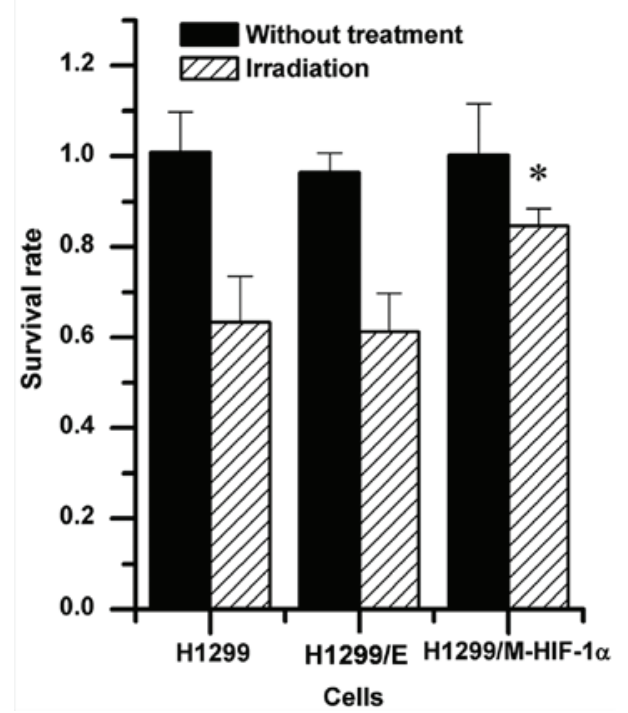

Figure 2. Observation of radioresistant H1299 cells. (A) Representative blots from three independent replicates are shown. (B) Expression of HIF-1 $\alpha$ in various groups of H1299 cells. (C) Alteration of the radiosensitivity of H1299 cells upon transfection with pcDNA3.0-EGFP-HIF-1 $\alpha$ plasmid. " $\mathrm{P}<0.05$, ${ }^{* * *} \mathrm{P}<0.01$ vs. H1299 cells. M, mutant; HIF-1 $\alpha$, hypoxia inducible factor- $1 \alpha$; E, empty.

The Bradford method was used to detect concentrations of protein in diverse samples. Protein concentration was measured using an automatic multifunctional microplate reader. Proteins $(50 \mu \mathrm{g})$ were separated by $8 \%$ SDS-polyacrylamide gel electrophoresis. The separated proteins were electrophoretically transferred to polyvinylidene difluoride membranes, which were then blocked with 5\% skim milk in Tris-buffered saline containing $0.1 \%$ Tween 20 at room temperature for $1 \mathrm{~h}$, and then incubated with mouse anti-HIF-1 $\alpha$ antibody (catalog no. ab82832; Abcam, Cambridge, MA, USA) at a 1:500 dilution overnight at $4^{\circ} \mathrm{C}$, followed by goat anti-mouse

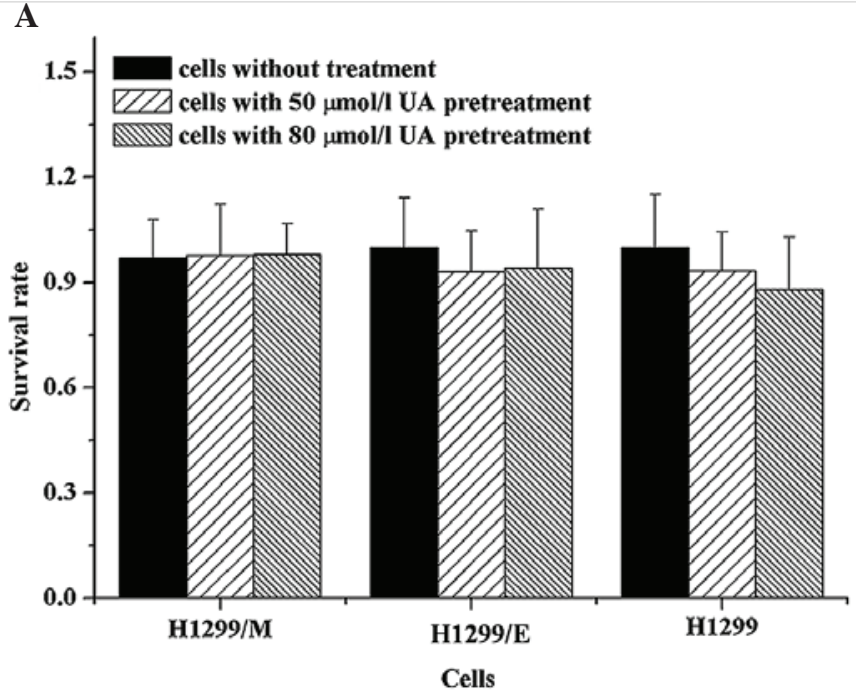

B

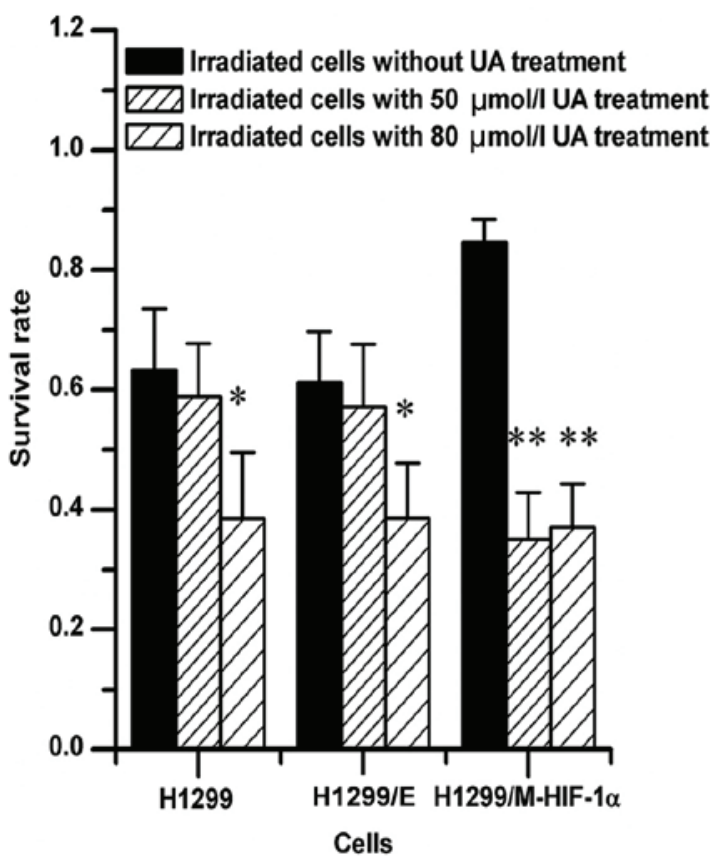

Figure 3. Radiosensitization effect of UA. (A) Influence of UA at different concentrations on NSCLC cells. (B) Survival rates of NSCLC cells upon treatment with UA in combination with irradiation. ${ }^{*} \mathrm{P}<0.05,{ }^{* * *} \mathrm{P}<0.01$ vs. irradiated cells without UA treatment. M, mutant; HIF-1 $\alpha$, hypoxia inducible factor-1 $\alpha$; UA, ursolic acid; NSCLC, non-small cell lung cancer; E, empty.

immunoglobulin G (catalog no. ab8226; Abcam) for $1 \mathrm{~h}$ at room temperature. Signals were detected with enhanced chemiluminescence (ECL Plus; GE Healthcare Life Sciences, Chalfont, UK). An antibody against the microtubule protein tubulin (anti-tubulin; Abcam) at a 1:1,000 dilution was used as an internal control to observe the changes in the HIF-1 $\alpha$ bands.

Intracellular GSH assay. Following the treatment of triplicate samples of $10^{6}$ cells with different reagents, the intracellular GSH content was measured with a glutathione reductase/5,5'-dithiobis-(2-nitrobenzoic acid) (DTNB) recycling assay kit obtained from Nanjing Jiancheng Bioengineering Research Institute (Nanjing, China), following the protocol recommended by the manufacturer. Briefly, GSH was determined using a reaction mixture containing $50 \mu \mathrm{l}$ of cell 


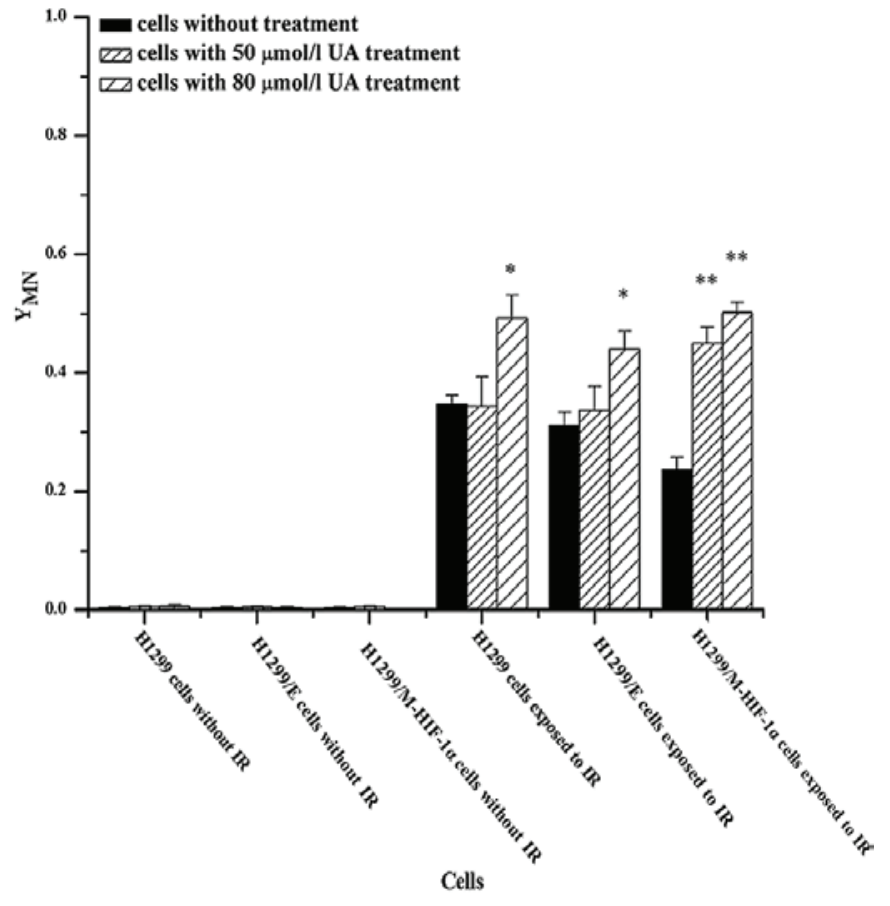

Figure 4. Influence of UA on the formation of micronuclei in irradiated cells. ${ }^{*} \mathrm{P}<0.05,{ }^{* *} \mathrm{P}<0.01$ vs. irradiated cells without UA treatment. $\mathrm{M}$, mutant; $\mathrm{Y}_{\mathrm{MN}}$; micronucleus yield; IR, irradiation; HIF-1 $\alpha$, hypoxia inducible factor- $1 \alpha$; UA, ursolic acid; E, empty.

lysates, $50 \mu \mathrm{l}$ of $2.4 \mathrm{mM}$ DTNB and $50 \mu \mathrm{l}$ of $10.64 \mathrm{mU} / \mu \mathrm{l}$ glutathione reductase in the assay buffer $(153 \mathrm{mM}$ sodium phosphate and $8.4 \mathrm{mM}$ ethylenediaminetetraacetic acid, $\mathrm{pH} 7.5$ ). After $5 \mathrm{~min}$ incubation at $25^{\circ} \mathrm{C}$, the reaction was started by the addition of $50 \mu \mathrm{l}$ of reduced nicotinamide adenine dinucleotide phosphate (NADPH) solution $(0.16 \mathrm{mg} / \mathrm{ml})$ in the assay buffer. The standard and the sample cuvettes were placed into a dual-beam spectrophotometer, and the increases in absorbance at $412 \mathrm{~nm}$ were followed as a function of time.

Measurement of intracellular ROS. Cell suspension from the different treatmentswas incubated with $10 \mu \mathrm{M}$ of 2',7'-dichlor o-dihydro-fluorescein diacetate (DCFH-DA) for $30 \mathrm{~min}$, and then washed three times with phosphate-buffered saline for removing excess DCFH probe. Upon counting the viable cells, the fluorescence intensities of the cells were observed under an inverted fluorescence microscope (Nikon Corporation, Tokyo, Japan), at excitation and emission wavelengths of 488 and $525 \mathrm{~nm}$, respectively.

Statistical analysis. Data are reported as the mean \pm standard error of the mean of three separate experiments unless stated otherwise. Statistical significance was measured by independent samples t-test and analysis of variance. $\mathrm{P}<0.05$ was considered to indicate a statistically significant difference.

\section{Results}

Identification of radioresistant NSCLC cells. The radiosensitivity of $\mathrm{H} 1299$ cells was regulated by transfecting recombinant pcDNA3.0-EGFP-HIF-1 $\alpha$ plasmid. As shown in Fig. 2A and $\mathrm{B}$, under aerobic conditions, overexpression of HIF-1 $\alpha$ was
A

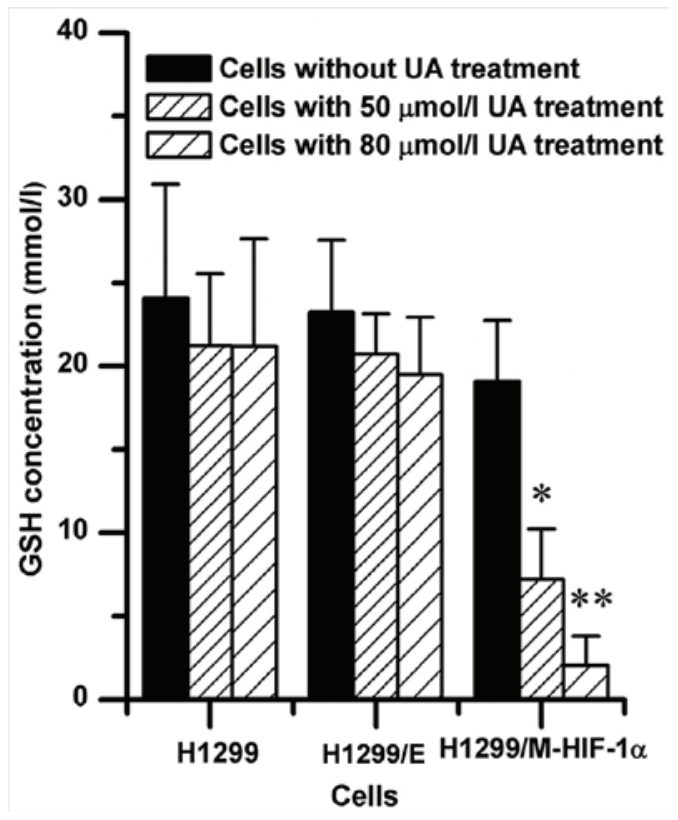

B

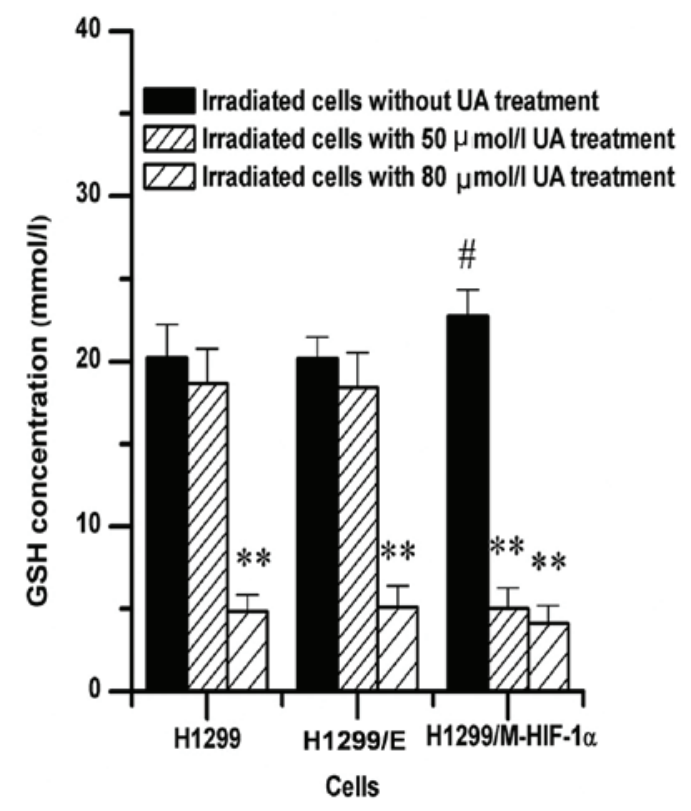

Figure 5. Alteration of endogenous GSH content in NSCLC cells by UA pretreatment. Experiments were repeated six times. (A) Levels of cellular GSH in NSCLC cells with UA treatment. (B) Levels of cellular GSH in NSCLC cells following combined treatment with UA and radiation. ${ }^{*} \mathrm{P}<0.05$ and ${ }^{* *} \mathrm{P}<0.01$ vs. cells without UA treatment; ${ }^{*} \mathrm{P}<0.05$ vs. irradiated $\mathrm{H} 1299$ cells or irradiated H1299/E cells. M, mutant; GSH, glutathione; HIF-1 $\alpha$, hypoxia inducible factor-1 $\alpha$; UA, ursolic acid; NSCLC, non-small cell lung cancer; E, empty.

detected in H1299 cells transfected with the H1299/M-HIF-1 $\alpha$ recombinant plasmid, named H1299/M-HIF-1 $\alpha$ cells. Both the parental H1299 cells and the H1299 cells transfected with empty vector (H1299/E cells) exhibited loss of HIF-1 $\alpha$ expression. Upon exposure to $2 \mathrm{~Gy}$ irradiation, cellular viability was significantly upregulated in H1299/M-HIF-1 $\alpha$ cells compared with that in H1299 and H1299/E cells (Fig. 2C). By contrast, no obvious difference was observed between H1299 cells and H1299/E cells. It was therefore demonstrated that H1299/M-HIF-1 $\alpha$ cells had lower radiosensitivity than H1299 cells and H1299/E cells. 
A

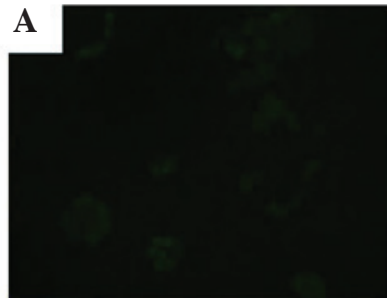

$\overline{\mathbf{E}}$

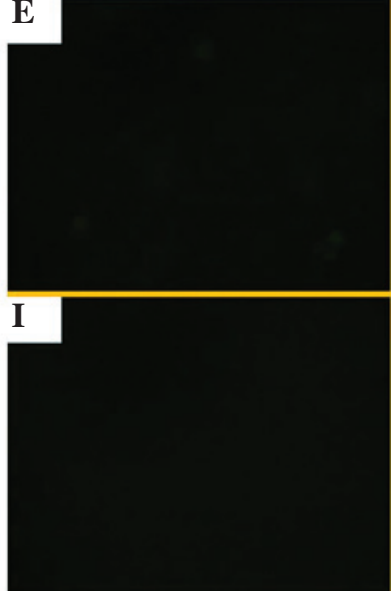

B

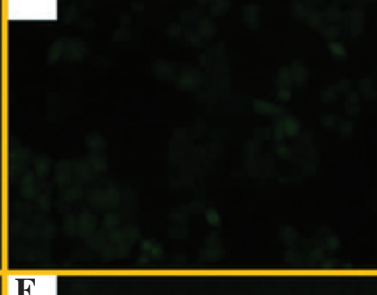

F

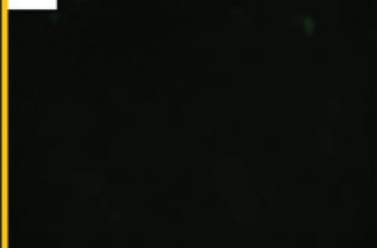

C

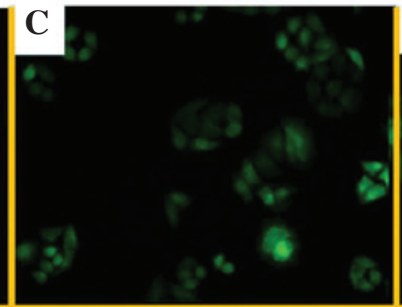

G
D

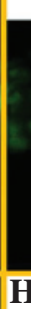

C.

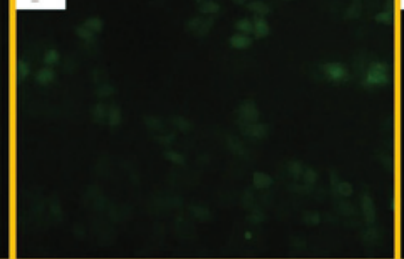

K

L
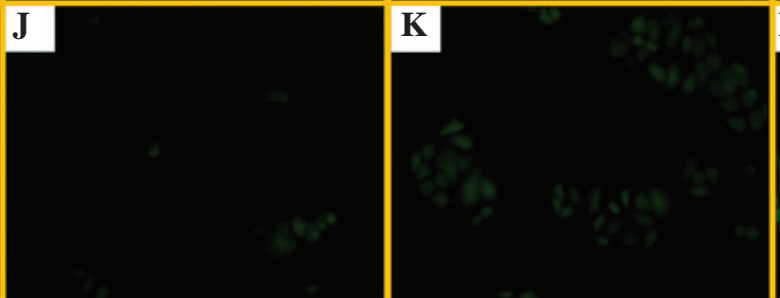

Figure 6. Alteration of the intracellular reactive oxygen species levels by ursolic acid treatment. (A) Blank control for H1299/M-HIF-1 $\alpha$ cells without DCFH-DA treatment. (B) Control for H1299/M-HIF-1 $\alpha$ cells with DCFH-DA treatment. (C) H1299/M-HIF-1 $\alpha$ cells with 50 $\mu$ mol/1 DCFH-DA treatment. (D) H1299/M-HIF-1 $\alpha$ cells with $80 \mu \mathrm{mol} / 1$ DCFH-DA treatment. (E) Blank control for H1299/E cells without DCFH-DA treatment. (F) Control for H1299/E cells with DCFH-DA treatment. (G) H1299/E cells with $50 \mu$ mol/1 DCFH-DA treatment. (H) H1299/E cells with 80 $\mu$ mol/1 DCFH-DA treatment. (I) Blank control for H1299 cells without DCFH-DA treatment. (J) Control for H1299 cells with DCFH-DA treatment. (K) H1299 cells with $50 \mu$ mol/1 DCFH-DA treatment. (L) H1299 cells with $80 \mu \mathrm{mol} / 1$ DCFH-DA treatment. Fluorescence microscope images were captured at x20 magnification. DCFH-DA, 2',7'-dichloro-dihydro-fluorescein diacetate; M, mutant; HIF-1 $\alpha$, hypoxia inducible factor-1 $\alpha$; E, empty.

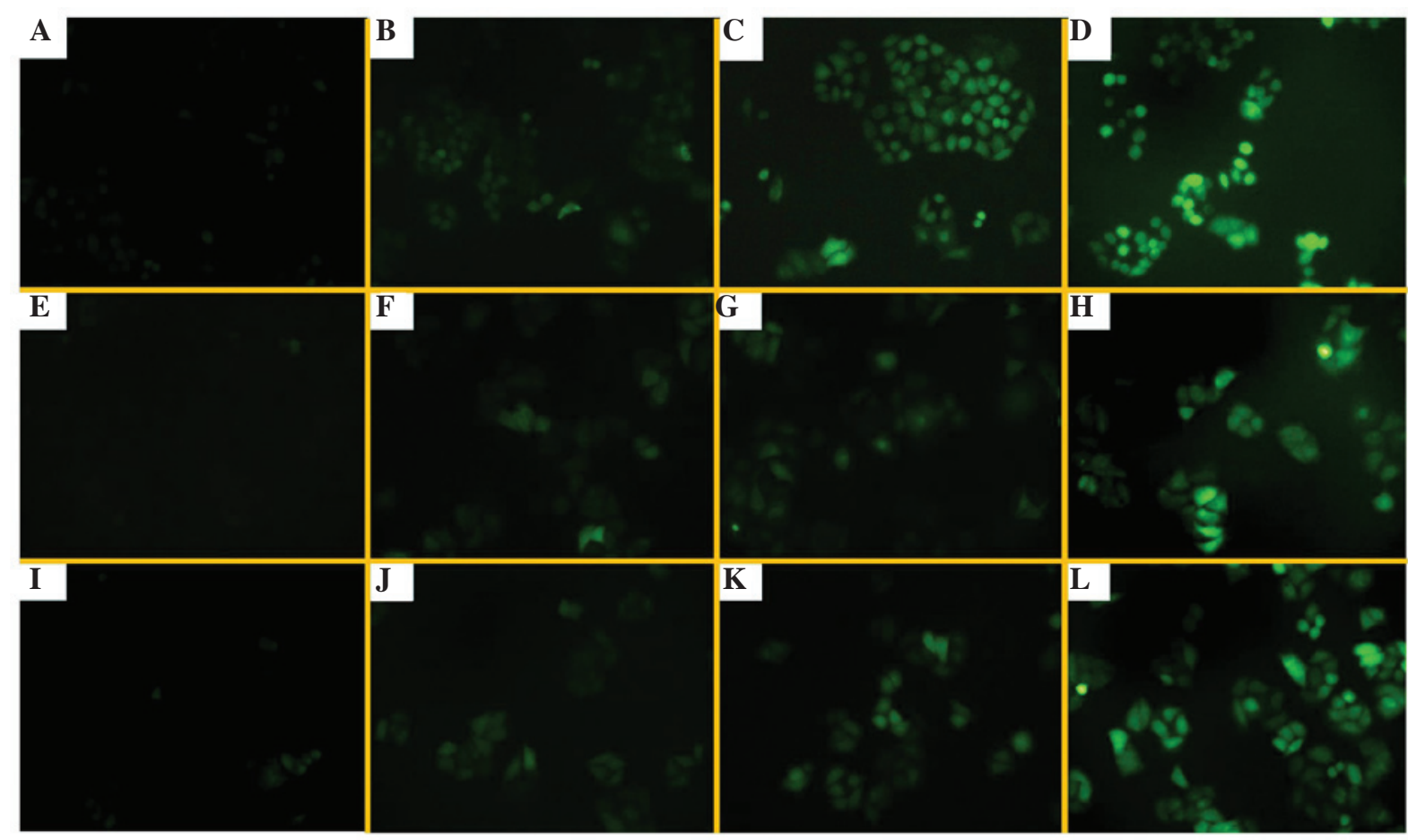

Figure 7. Alteration of intracellular reactive oxygen species levels by the combination of UA with irradiation treatment. (A) Control for H1299/M-HIF-1 $\alpha$ cells with DCFH-DA treatment. (B) H1299/M-HIF-1 $\alpha$ cells exposed to irradiation at 2 Gy. (C) H1299/M-HIF-1 $\alpha$ cells with the combination of $50 \mu$ mol/1 UA with radiation treatment. (D) H1299/M-HIF-1 $\alpha$ cells subjected to the combination of $80 \mu$ mol/l UA and radiation treatment. (E) Control for H1299/E cells with DCFH-DA treatment. (F) H1299/E cells exposed to irradiation at $2 \mathrm{~Gy}$. (G) H1299/E cells exposed to the combination of $50 \mu$ mol/1 UA with radiation treatment. (H) H1299/E cells subjected to the combination of $80 \mu \mathrm{mol} / 1 \mathrm{UA}$ and radiation treatment. (I) Control for H1299 cells with DCFH-DA treatment. (J) H1299 cells exposed to irradiation at $2 \mathrm{~Gy}$. (K) H1299 cells upon combination of $50 \mu \mathrm{mol} / 1$ UA with radiation treatment. (L) H1299 cells subjected to the combination of $80 \mu \mathrm{mol} / 1$ UA with radiation treatment. Fluorescence microscope images were captured at x20 magnification. DCFH-DA, 2',7'-dichloro-dihydro-fluorescein diacetate; M, mutant; HIF-1 $\alpha$, hypoxia inducible factor-1 $\alpha$; E, empty; UA, ursolic acid. 


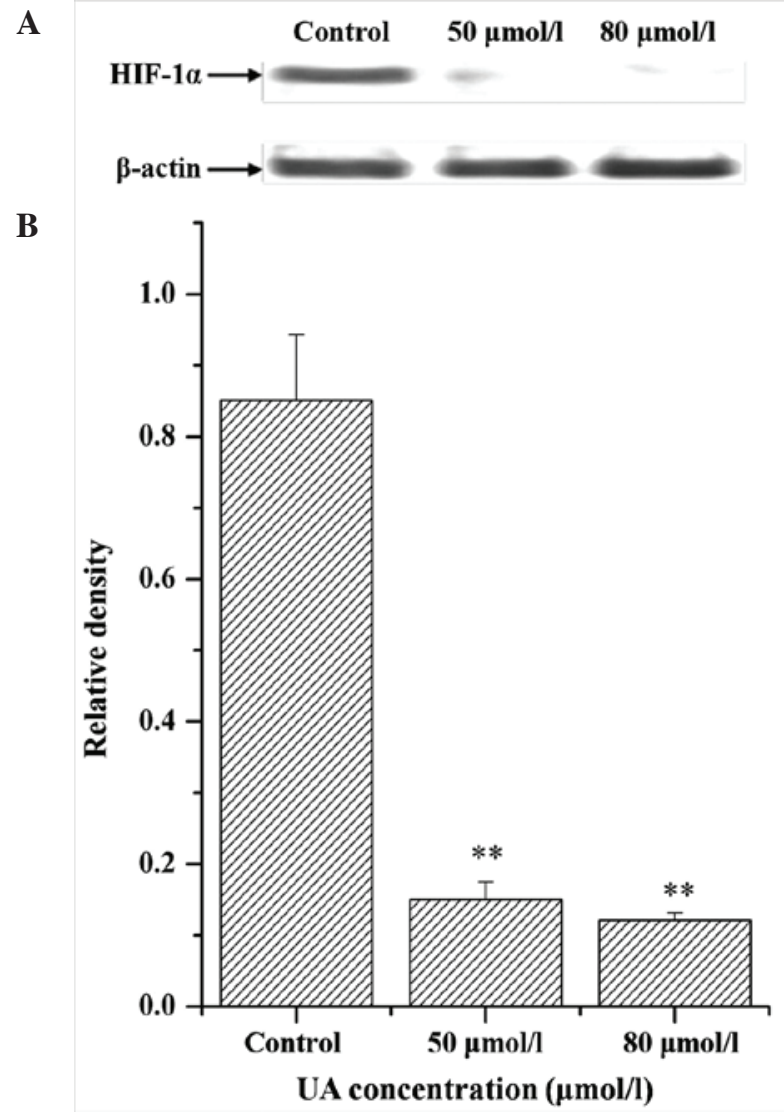

Figure 8. Change in hypoxia inducible factor-1 $\alpha$ expression upon ursolic acid treatment. (A) Representative images from three separate western blot experiments. (B) Statistical results of relative density. ${ }^{* *} \mathrm{P}<0.01$ vs. control. HIF-1 $\alpha$, hypoxia inducible factor- $1 \alpha$.

Influence of UA on the sensitivity of resistant NSCLC cells. To evaluate the radiosensitizing effect of UA on NSCLC cells, the experimental concentration of UA was first selected. The result from the cytotoxicity test indicated that there were not significant changes in the survival rates of the three types of NSCLC cells pretreated with UA at 50 and $80 \mu \mathrm{mol} / \mathrm{l}$, as shown in Fig. 3A. Alterations in the survival rates of the cells subjected to treatment with two different concentrations of UA for $24 \mathrm{~h}$ were detected upon irradiation at $2 \mathrm{~Gy}$. It was observed that UA at two different concentrations could significantly increase the radiosensitivity of H1299/M-HIF-1 $\alpha$ cells, leading to the reduction of survival rates of the irradiated cells. However, the radiosensitizing effects of UA on H1299 and H1299/E cells were only observed at high concentration (80 $\mu \mathrm{mol} / \mathrm{l})$ (Fig. 3B). Consequently, it was demonstrated that radioresistant NSCLC cells were the most sensitive to the UA treatment combined with irradiation.

Alteration of MN formation in irradiated NSCLC cells by $U A$ treatment. The $\mathrm{MN}$ frequencies in irradiated cells were further measured for the assessment of DNA damage. As shown in Fig. 4, when NSCLC cells were not exposed to ionizing radiation, the intracellular $\mathrm{MN}$ frequencies were very low, even with UA pretreatment. Conversely, the MN ratio increased in irradiated cells. Subsequently, the addition of UA at 50 and $80 \mu \mathrm{mol} / 1$ could further increase the formation of MN in irradiated H1299/M-HIF-1 $\alpha$ cells. Further elevation of MN frequencies, however, was not observed in H1299 or H1299/E cells subjected to the combination treatment of UA at $50 \mu \mathrm{mol} / 1$ concentration and radiation. It was thus obvious that UA effectively promoted the formation of MN in irradiated NSCLC cells, particularly in irradiated H1299/M-HIF-1 $\alpha$ cells.

Changes in intracellular GSH content by UA treatment. Due to the strong radioprotection of endogenous $\mathrm{GSH}$, the intracellular GSH content was analyzed in NSCLC cells upon non-exposure or exposure to irradiation following UA pretreatment. The results revealed that UA could remarkably decrease the endogenous GSH content in H1299/M-HIF-1 $\alpha$ cells not exposed to radiation but not in H1299 or H1299/E cells, as shown in Fig. 5A. Additionally, following NSCLC cells exposure to irradiation, the level of cellular GSH in H1299/M-HIF-1 $\alpha$ cells was higher than that in H1299 cell and H1299/E cells, as shown in Fig. 5B. Furthermore, UA at high concentration $(80 \mu \mathrm{mol} / \mathrm{l})$ could effectively attenuate the intracellular GSH content of H1299 and H1299/E cells. The combination treatment of UA with radiation could decrease the GSH intracellular contents in H1299/M-HIF-1 $\alpha$ cells, both at 50 and $80 \mu \mathrm{mol} / 1$ concentration of UA.

Alteration of intracellular ROS levels by UA treatment. Under an inverted fluorescence microscope, there was fluorescence in H1299/E and H1299/M-HIF-1 $\alpha$ cells without DCFH-DA probe treatment, due to the presence of EGFP in the transfected plasmid (Fig. 6A and E). The fluorescence intensities in the three groups of cells evaluated were weakly increased following DCFH-DA treatment. UA at different concentrations could enhance the levels of intracellular ROS and FR in these cells, particularly in H1299/M-HIF-1 $\alpha$ cells (Fig. 6). The results shown in Fig. 7 further demonstrate that the combination of UA with radiation treatment significantly enhanced the generation of ROS and FR. It was revealed that UA with or without irradiation could promote an increase in cellular ROS and FR, particularly in H1299/M-HIF-1 $\alpha$ cells.

Influence of UA on the expression of HIF-1 $\alpha$. Besides detection of intracellular GSH, the levels of HIF-1 $\alpha$ in radioresistant cells were investigated upon UA pretreatment. It was observed that UA at different concentrations markedly reduced the protein expression levels of HIF-1 $\alpha$, as detected by western blotting (Fig. 8). The results also revealed that UA could suppress the expression of M-HIF-1 $\alpha$.

\section{Discussion}

In our previous study, it was observed that oleanolic acid (OA), an isomer of UA, could effectively increase the radiosensitivity of aerobic and hypoxic A549 cells, a NSCLC cell line, by inhibition of intracellular GSH synthesis and HIF-1 $\alpha$ expression $(31,32)$. The radiosensitizing efficiency of UA on NSCLC cells, particularly on radioresistant cells, was also observed in the present study, due to the higher anti-tumor activity of UA compared with that of OA (33). In the current study, a radioresistant cell line was firstly established by transfection with an M-HIF-1 $\alpha$ plasmid. It is known that HIF-1 $\alpha$ is closely associated with the radiosensitivity of tumor cells, 
including NSCLC cells $(34,35)$. Numerous studies have shown that, following inhibition of the master transcription factor triggered in response to hypoxia, the radiotherapeutic effect on NSCLC may be significantly increased $(36,37)$. Under aerobic conditions, HIF-1 $\alpha$ is hydroxylated by prolyl hydroxylases at the proline residues 402 and 564 in the ODDD (38). Subsequently, it is targeted for proteasome-mediated degradation via a protein ubiquitin ligase complex containing the product of von Hippel-Lindau tumor suppressor (39). Another blockage pathway of HIF-1 $\alpha$ activity is hydroxylation of asparagine 803 by factor inhibiting HIF-1 within the CTAD, followed by interruption of the binding of HIF- $1 \alpha$ to the p300/CREB-binding protein coactivator, thus preventing the transactivation capabilities of HIF-1 (40). In the present study, the cDNA of HIF-1 $\alpha$ within the pcDNA3.0-EGFP-HIF-1 $\alpha$ recombinant plasmid contained three mutant sites, namely proline residues 402 and 564, and asparagine 803, which enable HIF-1 $\alpha$ to evade hydroxylation by maintaining HIF-1 $\alpha$ expression and transcriptional activity under aerobic conditions. Thus, H1299/M-HIF-1 $\alpha$ cells exhibited high level of HIF-1 $\alpha$ under aerobic conditions, concomitant with a refractory response to radiation (41). This in vitro model is convenient to observe alteration of the sensitivity of resistant cells to radiation, as HIF-1 $\alpha$ need not be induced by physical or chemical hypoxia.

As a natural antitumor drug, the activity of UA has been reported in numerous studies $(22,23,42)$. Previous data reported the sensitization of cancer cells to ionizing radiation-induced apoptosis by UA, including human prostate cancer DU145 cells, mouse colon cancer CT26 cells and mouse melanoma B16F10 cells (28). The present study demonstrated that UA exerted a similar radiosensitizing effect on NSCLC cells. Notably, a stronger sensitizing effect of UA was observed on radioresistant H1299 cells with high level of HIF-1 $\alpha$ expression compared with that observed in H1299 cells without HIF-1 $\alpha$ expression. Similarly, sensitization to ionizing radiation of radioresistant tumor cells was previously observed to be effected by other natural or synthetic compounds $(43,44)$. For instance, Biddlestone-Thorpe et al (43) reported that glioma cells with a mutant p53 gene that induced tolerance to radiation were markedly more sensitive to radiosensitization induced by KU-60019 (an ataxia telangiectasia mutated kinase inhibitor) than genetically matched wild-type glioma cells. The mechanism could be associated with changes in the expression of various genes and modification of intracellular homeostasis.

There are numerous studies demonstrating that the numbers and frequencies of intracellular MN represent DNA damage induced by radiation; thus MN is considered as an appropriate biological tool to evaluate in vitro radiosensitivity due to its high reliability and reproducibility (45-47). Based on the results of the present cell viability assay, intracellular MN frequencies were detected as a biomarker of DNA damage caused by ionizing radiation. The results revealed that the intracellular MN formation was in agreement with the change in tendency observed in the cell viability assay. Both 50 and $80 \mu \mathrm{mol} / 1$ of UA could increase the MN frequencies in binucleated H1299/M-HIF-1 $\alpha$ cells following irradiation. By contrast, elevation of $\mathrm{MN}$ formation in irradiated H1299 cells and H1299/E cells was only observed with a UA concentration of $80 \mu \mathrm{mol} / 1$. These findings indicate the marked sensitization caused by UA on radioresistant NSCLC cells.

According to previous studies, the depletion of GSH content strongly resulted in the production of cellular $\mathrm{MN}$ and the death of irradiated NSCLC cells by increasing the levels of cellular ROS and FR $(31,32,48)$. Thus, the present study measured the intracellular GSH content and the levels of ROS and FR through either UA treatment alone or combination treatment with UA and irradiation. The results indicated that treatment of UA alone decreased the GSH content and increased the levels of ROS and FR in H1299/M-HIF-1a cells, but not in H1299 cells or H1299/E cells, whereas the combination of UA at high concentration $(80 \mu \mathrm{mol} / \mathrm{l})$ and irradiation could diminish the GSH content and increase the levels of ROS and FR in H1299 cells and H1299/E cells. For H1299/M-HIF-1 $\alpha$ cells, either exposed to irradiation or not, there was a reduction in cellular GSH content, concomitant with an enhancement in ROS and FR, following treatment with UA at various concentrations. To explore the mechanism behind these observations, the expression of HIF-1 $\alpha$ in H1299/M-HIF-1 $\alpha$ cells was detected upon UA treatment. It was observed that increasing HIF-1 $\alpha$ expression was inhibited by UA, which is in agreement with previously reported data $(49,50)$. According to the study by Guo et al $(51)$, the inhibition of HIF-1 $\alpha$ could decrease the cellular GSH content and increase the generation of ROS by regulating the level of $\mathrm{NADPH}$, which led to a more oxidizing environment for the cells. In present study, the GSH content of H1299/M-HIF-1 $\alpha$ cells could further be reduced due to UA-mediated suppression of HIF- $1 \alpha$ expression. Therefore, the increased sensitization of H1299/M-HIF-1 $\alpha$ cells by UA was associated with reduced HIF-1 $\alpha$ expression.

In summary, the present results demonstrated that UA significantly exerted a radiosensitizing effect on NSCLC cells, particularly on radioresistant cells overexpressing HIF-1 $\alpha$. The primary mechanism is explained as follows: i) Radiosensitivity of NSCLC cells without HIF-1 $\alpha$ expression was upregulated through UA, which decreased the intracellular GSH content; and ii) two pathways, including the attenuation of GSH and the suppression of HIF-1 $\alpha$ by UA, enhanced the sensitization towards ionizing radiation-induced cell death of NSCLC cells overexpressing HIF-1 $\alpha$. UA should therefore be deeply studied as a potential radiosensitizing reagent for NSCLC radiotherapy.

\section{Acknowledgements}

The present study was funded by the Anhui Provincial Natural Science Foundation of China (Hefei, China; grant no. $11040606 \mathrm{M} 210)$.

\section{References}

1. Senthi S, Haasbeek CJ, Slotman BJ and Senan S: Outcomes of stereotactic ablative radiotherapy for central lung tumours: A systematic review. Radiother Oncol 106: 276-282, 2013.

2. Shen Z, Wu X, Wang Z, Li B and Zhu X: Effect of miR-18a overexpression on the radiosensitivity of non-small cell lung cancer. Int J Clin Exp Pathol 8: 643-648, 2015. 
3. Subtil FS, Wilhelm J, Bill V, Westholt N, Rudolph S, Fischer J, Scheel S, Seay U, Fournier C, Taucher-Scholz G, et al: Carbon ion radiotherapy of human lung cancer attenuates HIF-1 signaling and acts with considerably enhanced therape-utic efficiency. FASEB J 28: 1412-1421, 2014.

4. Cannon DM, Mehta MP, Adkison JB, Khuntia D, Traynor AM, Tomé WA, Chappell RJ, Tolakanahalli R, Mohindra P, Bentzen SM and Cannon GM: Dose-limiting toxicity after hypofractionated dose-escalated radiotherapy in non-small-cell lung cancer. J Clin Oncol 31: 4343-4348, 2013.

5. Kim E, Youn H, Kwon T, Son B, Kang J, Yang HJ, Seong KM, Kim W and Youn B: PAK1 tyrosine phosphorylation is required to induce epithelial-mesenchymal transition and radioresistance in lung cancer cells. Cancer Res 74: 5520-5531, 2014.

6. Sekhar KR, Benamar M, Venkateswaran A, Sasi S, Penthala NR, Crooks PA, Crooks PA, Hann SR, Geng L, Balusu R, et al: Targeting nucleophosmin 1 represents a rational strategy for radiationsensitization. Int J Radiat Oncol Biol Phys 89: 1106-1114 2014.

7. Theys J, Yahyanejad S, Habets R, Span P, Dubois L, Paesmans K, Kattenbeld B, Cleutjens J, Groot AJ, Schuurbiers OC, et al: High $\mathrm{NOTCH}$ activity induces radiation resistance in non small cell lung cancer. Radiother Oncol 108: 440-445, 2013.

8. Okaichi K, Nose K, Kotake T, Izumi N and Kudo T: Phosphorylation of p53 modifies sensitivity to ionizing radiation. Anticancer Res 31: 2255-2258, 2011.

9. Jamal M, Rath BH, Williams ES, Camphausen K and Tofilon PJ: Microenvironmental regulation of glioblastoma radioresponse. Clin Cancer Res 16: 6049-6059, 2010.

10. Ayouaz A, Raynaud C, Heride C, Revaud D and Sabatier L: Telomeres: Hallmarks of radiosensitivity. Biochimie 90: 60-72, 2008.

11. Quintana-Cabrera R and Bolaños JP: Glutathione and $\gamma$-glutamylcysteine in the antioxidant and survival functions of mitochondria. Biochem Soc Trans 41: 106-110, 2013.

12. Pereira CV, Nadanaciva S, Oliveira PJ and Will Y: The contribution of oxidative stress to drug-induced organ toxicity and its detection in vitro and in vivo. Expert Opin Drug Metab Toxicol 8: 219-237, 2012

13. Slemmer JE, Shacka JJ, Sweeney MI and Weber JT: Antioxidants and free radical scavengers for the treatment of stroke, traumatic brain injury and aging. Curr Med Chem 15: 404-414, 2008

14. Wells PG, Bhuller Y, Chen CS, Jeng W, Kasapinovic S, Kennedy JC, Kim PM, Laposa RR, McCallum GP, Nicol CJ, et al: Molecular and biochemical mechanisms in teratogenesis involving reactive oxygen species. Toxicol Appl Pharmacol 207 (2 Suppl): 354-366, 2005

15. Ogunrinu TA and Sontheimer H: Hypoxia increases the dependence of glioma cells on glutathione. J Biol Chem 285 37716-37724, 2010

16. Honda T, Coppola S, Ghibelli L, Cho SH, Kagawa S, Spurgers KB, Brisbay SM, Roth JA, Meyn RE, Fang B and McDonnell TJ: GSH depletion enhances adenoviral bax-induced apoptosis in lung cancer cells. Cancer Gene Ther 11: 249-255, 2004

17. Lee JH, Tak JK, Park KM and Park JW: N-t-Butyl hydroxylamine regulates ionizing radiation-induced apoptosis in U937 cells. Biochimie 89: 1509-1516, 2007.

18. Karthikeyan S, Kanimozhi G, Prasad NR and Mahalakshmi R: Radiosensitizing effect of ferulic acid on human cervical carcinoma cells in vitro. Toxicol In Vitro 25: 1366-1375, 2011

19. Keshmiri-Neghab H, Goliaei B and Nikoofar A: Gossypol enhances radiation induced autophagy in glioblastoma multiforme. Gen Physiol Biophys 33: 433-442, 2014.

20. Elbaz HA, Lee I, Antwih DA, Liu J, Hüttemann M and Zielske SP: Epicatechin stimulates mitochondrial activity and selectively sensitizes cancer cells to radiation. PLoS One 9: e88322, 2014.

21. Zang LL, Wu BN, Lin Y, Wang J, Fu L and Tang ZY: Research progress of ursolic acid's anti-tumor actions. Chin J Integr Med 20: 72-79, 2014.

22. Wang W, Zhao C, Jou D, Lü J, Zhang C, Lin L and Lin J: Ursolic acid inhibits the growth of colon cancer-initiating cells by targeting STAT3. Anticancer Res 33: 4279-4284, 2013.

23. Huang CY, Lin CY, Tsai CW and Yin MC: Inhibition of cell proliferation, invasion and migration by ursolic acid in human lung cancer cell lines. Toxicol In Vitro 25: 1274-1280, 2011.

24. Park JH, Kwon HY, Sohn EJ, Kim KA, Kim B, Jeong SJ, Song JH, Koo JS and Kim SH: Inhibition of Wnt/ $\beta$-catenin signaling mediates ursolic acid-induced apoptosis in PC-3 prostate cancer cells. Pharmacol Rep 65: 1366-1374, 2013.
25. Xavier CP, Lima CF, Pedro DF, Wilson JM, Kristiansen K and Pereira-Wilson C: Ursolic acid induces cell death and modulates autophagy through JNK pathway in apoptosis-resistant colorectal cancer cells. J Nutr Biochem 24: 706-712, 2013.

26. Li J, Liang X and Yang X: Ursolic acid inhibits growth and induces apoptosis in gemcitabine-resistant human pancreatic cancer via the JNK and PI3K/Akt/NF-kB pathways. Oncol Rep 28: 501-510, 2012.

27. Li Y, Xing D, Chen Q and Chen WR: Enhancement of chemotherapeutic agent-induced apoptosis by inhibition of NF-kappaB using ursolic acid. Int J Cancer 127: 462-473, 2010

28. Koh SJ, Tak JK, Kim ST, Nam WS, Kim SY, Park KM and Park JW: Sensitization of ionizing radiation-induced apoptosis by ursolic acid. Free Radic Res 46: 339-345, 2012.

29. Huq F, Yu JQ, Beale P, Chan C, Arzuman L, Nessa MU and Mazumder ME: Combinations of platinums and selected phytochemicals as a means of overcoming resistance in ovarian cancer. Anticancer Res 34: 541-545, 2014.

30. Romm H, Barnard S, Boulay-Greene H, De Amicis A, De Sanctis S, Franco M, Herodin F, Jones A, Kulka U, Lista F, et al: Laboratory intercomparison of the cytokinesis-block micronucleus assay. Radiat Res 180: 120-128, 2013.

31. Qi R, Jin W, Wang J, Yi Q, Yu M, Xu S and Jin W: Oleanolic acid enhances the radiosensitivity of tumor cells under mimetic hypoxia through the reduction in intracellular GSH content and HIF-1 $\alpha$ expression. Oncol Rep 31: 2399-2406, 2014.

32. Wang J, Yu M, Xiao L, Xu S, Yi Q and Jin W: Radiosensitizing effect of oleanolic acid on tumor cells through the inhibition of GSH synthesis in vitro. Oncol Rep 30: 917-924, 2013.

33. Shan JZ, Xuan YY, Ruan SQ and Sun M: Proliferation-inhibiting and apoptosis-inducing effects of ursolic acid and oleanolic acid on multi-drug resistance cancer cells in vitro. Chin J Integr Med 17: 607-611, 2011.

34. Berghoff AS, Ilhan-Mutlu A, Wöhrer A, Hack1 M, Widhalm G, Hainfellner JA, Dieckmann K, Melchardt T, Dome B, Heinzl H, et al: Prognostic significance of Ki67 proliferation index, HIF1 alpha index and microvascular density in patients with non-small cell lung cancer brain metastases. Strahlenther Onkol 190: 676-685, 2014.

35. Yoshimura M, Itasaka S, Harada $\mathrm{H}$ and Hiraoka M: Microenvironment and radiation therapy. Biomed Res Int 2013: 685308, 2013

36. van Baardwijk A, Dooms C, van Suylen RJ, Verbeken E, Hochstenbag M, Dehing-Oberije C, Rupa D, Pastorekova S, Stroobants S, Buell U, et al: The maximum uptake of (18) F-deoxyglucose on positron emission tomography scan correlates with survival, hypoxia inducible factor-1alpha and GLUT-1 in non-small cell lung cancer. Eur J Cancer 43: 1392-1398, 2007.

37. Zeng L, Ou G, Itasaka S, Harada H, Xie X, Shibuya K, Kizaka-Kondoh S, Morinibu A, Shinomiya K and Hiraoka M: TS-1 enhances the effect of radiotherapy by suppressing radiation-induced hypoxia-inducible factor-1 activation and inducing endothelial cell apoptosis. Cancer Sci 99: 2327-2335, 2008.

38. Rolfo A, Many A, Racano A, Tal R, Tagliaferro A, Ietta F, Wang J, Post M and Caniggia I: Abnormalities in oxygen sensing define early and late onset preeclampsia as distinct pathologies. PLoS One 5: e13288, 2010.

39. Semenza GL: HIF-1 mediates metabolic responses to intratumoral hypoxia and oncogenic mutations. J Clin Invest 123: 3664-3671, 2013

40. Jin WS, Kong ZL, Shen ZF, Jin YZ, Zhang WK and Chen GF: Regulation of hypoxia inducible factor- $1 \alpha$ expression by the alteration of redox status in HepG2 cells. J Exp Clin Cancer Res 30: 61, 2011.

41. Wei L, Lu J, Feng L, Li S, Shan J and Li Y: Construction of recombinant adenovirus vector containing a modified gene that codes for human hypoxia-inducible factor-1alpha without oxygen-dependent degradation. Plasmid 63: 20-26, 2010.

42. Kassi E, Sourlingas TG, Spiliotaki M, Papoutsi Z, Pratsinis H, Aligiannis $\mathrm{N}$ and Moutsatsou P: Ursolic acid triggers apoptosis and Bcl-2 downregulation in MCF-7 breast cancer cells. Cancer Invest 27: 723-733, 2009.

43. Biddlestone-Thorpe L, Sajjad M, Rosenberg E, Beckta JM, Valerie NC, Tokarz M, Adams BR, Wagner AF, Khalil A, Gilfor D, et al: ATM kinase inhibition preferentially sensitizes p53-mutant glioma to ionizing radiation. Clin Cancer Res 19: 3189-3200, 2013.

44. Kim JC, Ali MA, Nandi A, Mukhopadhyay P, Choy H, Cao C and Saha D: Correlation of HER1/EGFR expression and degree of radiosensitizing effect of the HER1/EGFR-tyrosine kinase inhibitor erlotinib. Indian J Biochem Biophys 42: 358-365, 2005. 
45. Kashino G,Prise KM, Suzuki K, Matsuda N, Kodama S, Suzuki M, Nagata K, Kinashi Y, Masunaga S, Ono K and Watanabe M: Effective suppression of bystander effects by DMSO treatment of irradiated CHO cells. J Radiat Res 48: 327-333, 2007.

46. Thierens H and Vral A: The micronucleus assay in radiation accidents. Ann Ist Super Sanita 45: 260-264, 2009.

47. Romm H,Barnard S,Boulay-Greene H,De Amicis A,De Sanctis S, Franco M, Herodin F, Jones A, Kulka U, Lista F, et al: Laboratory intercomparison of the cytokinesis-block micronucleus assay. Radiat Res 180: 120-128, 2013.

48. Singh A, Bodas M, Wakabayashi N, Bunz F and Biswal S: Gain of Nrf2 function in non-small-cell lung cancer cells confers radioresistance. Antioxid Redox Signal 13: 1627-1637, 2010.
49. Das B, Yeger H, Tsuchida R, Torkin R, Gee MF, Thorner PS, Shibuya M, Malkin D and Baruchel S: A hypoxia-driven vascular endothelial growth factor/Flt1 autocrine loop interacts with hypoxia-inducible factor-1alpha through mitogen-activated protein kinase/extracellular signal-regulated kinase 1/2 pathway in neuroblastoma. Cancer Res 65: 7267-7275, 2005.

50. Lin CC, Huang CY, Mong MC, Chan CY and Yin MC: Antiangiogenic potential of three triterpenic acids in human liver cancer cells. J Agric Food Chem 59: 755-762, 2011.

51. Guo S, Miyake M, Liu KJ and Shi H: Specific inhibition of hypoxia inducible factor 1 exaggerates cell injury induced by in vitro ischemia through deteriorating cellular redox environment. J Neurochem 108: 1309-1321, 2009. 